\title{
Line-Storm Ludic System: An Interactive Augmented Stylus and Writing Pad for Creative Soundscape
}

\author{
Hans Cox \\ Department of Computer \\ Science \\ University of Colorado \\ Colorado Springs, $\mathrm{CO}$ \\ 80918, USA \\ hcox@uccs.edu
}

\author{
Sudhanshu Kumar \\ Semwal \\ Department of Computer \\ Science \\ University of Colorado \\ Colorado Springs, $\mathrm{CO}$ \\ 80918, USA \\ ssemwal@uccs.edu
}

\begin{abstract}
We present Line-Storm, an interactive computer system for creative performance. The context we investigated was writing on paper using Line-Storm. We used self-report questionnaires as part of research involving human participants, to evaluate Line-Storm. LineStorm consisted of a writing stylus and writing pad, augmented with electronics. The writing pad was connected to a contact microphone, and the writing stylus had a small micro-controller board and peripherals attached to it. The signals from these electronic augmentations were fed into the audio-synthesis environment Max/MSP to produce an interactive soundscape. We attempted to discover whether Line-Storm enhanced a self-reported sense of being present and engaged during a writing task, and we compared Line-Storm to a noninteractive control condition. After performing statistical analysis in SPSS, participants reported they were, on average, no more present and engaged during the experimental condition than during the control condition. As creativity is subtle, and varies with person, time, context, space and so many other factors, this result was somewhat expected by us. A statistically significant result of our study is that some participants responded to Line-Storm more positively than others. These Preservers of Line-Storm were a group, distinct from other participants, who reported greater presence and engagement and who wrote more words with LineStorm and during the control condition. We discuss the results of our research and place Line-Storm in an artistic-technological context, drawing upon writings by Martin Heidegger when considering the nature of Line-Storm. Future work includes interesting, immer-
\end{abstract}

\footnotetext{
Permission to make digital or hard copies of all or part of this work for personal or classroom use is granted without fee provided that copies are not made or distributed for profit or commercial advantage and that copies bear this notice and the full citation on the first page. To copy otherwise, or republish, to post on servers or to redistribute to lists, requires prior specific permission and/or a fee.
}

sive, and engaging interactive soundscape for writing or drawing performance, modifying interactive components, improving aesthetics, using more miniaturized electronics, and experimenting with a drawing task instead of a writing task.

\section{Keywords}

Ludic System, Creativity, Interactive Soundscape

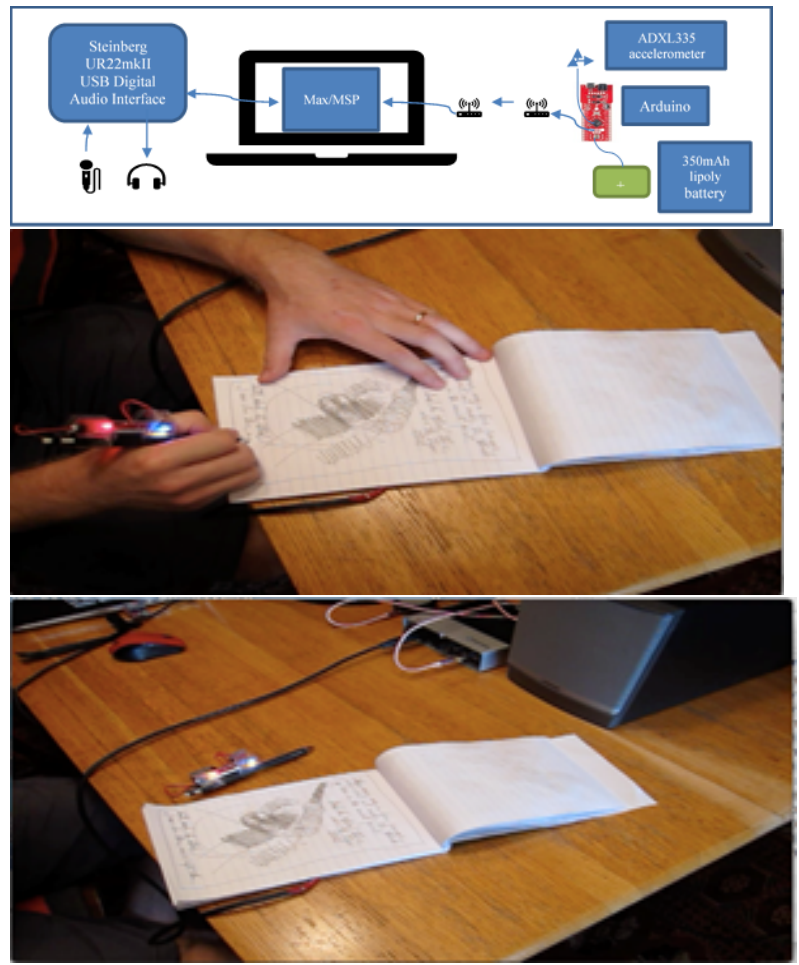

Figure 1: a (above): Line-Storm A System Diagram. Fig. 1b-c (below) Line storm stylus drawing and sample of creative content

\section{INTRODUCTION}

Tod Machover [1-22] [40] has emphasized the need to augment existing, traditional musical instruments while 
ensuring these augmentations act as stimuli to the creative process, not simply as additional features. One focus of this paper is to find a way to enhance human creativity. Another is to observe the emergence of the work when the system is used. A third, is our attempt to make something that is fun to use. We have conceived, designed, constructed, evaluated, our system called LineStorm ${ }^{1}$, attempting to enhance a sense of both presence and engagement in the user. Only through performance with Line-Storm, does Line-Storm come into being.

The method of experience sampling-interrupting a person as they go through their daily activities and asking questions about their experience-has been used to find that when people's minds are wandering, they are less happy [37]. "Be Here Now," a mantra popularized in the United States by, for example, Dr. Richard Alpert [16], who became Baba Ram Dass. This mantra now occurs in a leading business publication urging middle managers everywhere to "be present" to be a "great leader" [29] and presumably to reap the rewards of "success." Even the LSD experimentation Dass describes in Be Here Now, carried out on a small, socially acceptable scale in Silicon Valley, where tech workers "microdose" themselves with LSD, to enhance their creativity and improve interpersonal interactions [38]. Some esoteric practices leading to creative work may conjure images of the lone painter or poet, or of a sculptor in her studio. It is not only Silicon Valley technocrats, scrambling for millions and billions of dollars, who might benefit from enhancing human creativity.

Even now one is ashamed of resting, and prolonged reflection almost gives people a bad conscience. One thinks with a watch in one's hand, while eating meals, and reading the latest news of the stock market; we live today not to miss out on anything. -Nietzsche [45]

Note that Nietzsche was writing well over 100 years before "FOMO," or "fear of missing out," became an expression related to early 21 st-century smartphone users. Our point is that we recognize that there are different meanings to the phrase creative work. For example, billionaires and poets are not endorsing the same thing when both use the word "creative" or the word "work," though both may praise "creative work."

Some decry the extreme measures taken by LSD trippers in the 1960s [38], and want to turn the drug into an effective money-making tool. An irony is that creative work translates into fortunes undreamt of by poets such as Robert Frost. There is a story in which Joseph Heller, author of the novel Catch-22, when told of an investment banker who had made more money last

\footnotetext{
${ }^{1}$ We chose the name Line-Storm after a favorite Robert Frost poem, "A Line-Storm Song."
}

year than he might ever to be expected to make from the novel, replied that he had something the investment banker would never have: enough. So, we argue that it is possible that what was good for Heller, in the anecdote, would probably not have been good for the investment banker, even when the concept of creative work is broadened to include both their endeavors. Enhancing one type of creative work may not enhance the other. The ecstasy of the composer remarked upon by Csikszentmihalyi [14] or of the novelist, may not be found in the same way the "A-ha!" of the software developer is found.

Our work involving Line-Storm has been an attempt to provide a ludic system for use by the creative worker. Gaver [21] defines a ludic system as one that is used for its own sake, and not for some other end. By attempting to increase a user's sense of presence and engagementtheir being here now-our hope is to provide an immersive environment in which to do creative work with a writing stylus such as the mechanical pencil we chose to use. Taskscape is a complex term from Ingold's "The Temporality of the Landscape" [32], which we will refer to later, when speaking of the new possibilities of a task that Line-Storm exposes, as affordances in Gibson's sense of the term[19]. One of our committee members, a professor of music, suggested that our work involves the taskscape of the creative worker, working with a writing stylus and paper. This taskscape includes the place, people, and objects surrounding the creative worker doing creative work. The taskscape is social [32]. The experience of the user of our system, and of the research participants who gave of their time to be a part of this paper, is a social experience, and the writing tasks they performed are tasks that fit into "an array of activities"-which include the writing of this sentence [32]. We do not know-as above, because too little work has been done in this area-whether the taskscape of a user of Line-Storm is altered in ways more conducive to writing poetry than to the drafting of microprocessor plans, for example, or vice versa. Rather than devise a completely new tool, we have chosen to augment an otherwise ordinary mechanical pencil ${ }^{2}$. Perhaps by looking away from our goal, creative enhancement-as we must when looking at faint night-sky objects with the naked eye [55]-and making the use of the system the primary activity, and the work done with it a secondary activity, we think we will find ourselves progressing in that direction, whereas a direct approach would not have succeeded. By giving a chance for play, we have hoped our system, Line-Storm, serves as stim-

${ }^{2}$ We could have similarly augmented a paintbrush or a pen, though the paintbrush would have required a different approach. We depend in part on the sounds made by the user's touching of the writing pad, and we cannot expect a paintbrush to make the same level of sound made by a pencil lead. 
ulant and facilitator "to the creative process itself," as Machover [40] advises.

\section{RELATED WORK}

Line-Storm is not digital art as such. Its products are physical objects and phenomena. They are (analog) drawings or writings. It produces sounds, which arethough digitally mediated-analog sounds. The computer is, in Line-Storm, an intermediary and a facilitator, with a visual arts component and sound, satisfying criteria for Demers' [8] second sub-genre of sound art. Line-Storm amplifies and augments the sonic aspects. The sounds made, while writing or drawing, are captured using a contact microphone and are played through headphones. Sounds of natural phenomenathe sounds of a thunderstorm-augment the writing or drawing experience. These sounds are recorded analog yet are digitally mediated.

\subsubsection{Line-Storm as Performance}

Line-storm can be used as a form of interactive theater. Line-Storm is a piece of evolving art and/or in play [52]. A performer using Line-Storm may be using it for different reasons, including for the fun of using it, to write a letter to a friend, to write down a cooking recipe, to write poetry, to draw, because it is a curious thing one wants to understand, or for other reasons. A performance occurs "as action, interaction, and relation" [52]. Line-Storm is an interactive system, where the performer's actions cause sounds to occur, which may influence subsequent actions. The sounds can be controlled to some degree, by the performer. The drawing or writing produced during performance is one product of the performance. The sounds, which can be recorded and played back, are another product. The audience of the performance may be the performer alone, or a person or persons witnessing the performance as it occurs, or presented with one or more products of the performance, the written or drawn product or the sound produced. Line-Storm is a way of "honoring the ordinary" in Schechner's [52] words.

Play is a way of introducing flow into one's life [53] and has an organic quality. Sounds which we added to LineStorm included those of thunderstorms, which have organic qualities similar to movement of air through a room, or sounds from nearby birds. Thunderstorms followed by quiet rain can be theraputic to some as well. We wanted to use analog (thunderstorm) sounds for our analog ludic system as well. The digital medium is one of permanence and impermanence. One motivation of Line-Storm is that it could preserve the practice of the handwritten letter.

Previous work, that investigated augmenting a writing stylus with electronic or computer systems, includes
MusicGrip [23], a pressure-sensor-controlled system in which a writing stylus was used to control analog synthesizers. Musc Grip used a one-to-one correspondence between sensor input and synthesizer output. Shichinohe et al. [54] used a camera system to implement an augmented-reality system to aid in the instruction of calligraphic writing. Their system monitored brush position and body posture, providing both ambient (color) feedback and verbal feedback. Part of a performance-the Brain Opera-the Digital Baton was a wireless baton, augmented with sensors, used as a New Interface for Musical Expression (NIME) [46]. The baton carried an infrared LED at its tip, pressure-sensitive resistors that were controlled by the performer's fingers gripping the baton, and three $+/-5 \mathrm{~g}$ accelerometers. These inputs were mapped to musical parameters. The Digital Baton was a wired NIME, but the authors did discuss what could be done to make it wireless. Tod Machover's work with hyperinstruments (electronic augmentations of traditional music instruments) [42]) and [40] are very interesting. Machover's Hyperstring Trilogy [41] was composed and performed using hyperinstruments-hypercello, hyperviolin, and hyperviola-which were traditional classical instruments augmented with sensors. Machover's philosophy of augmenting, and not replacing, traditional tools, is one we have followed in our work [42]. LiveScribe (http://www.livescribe.com), which has produced a wireless pen with handwriting recognition, no longer develops the electronic writing pen it once did, so we did not involve the company's work in our work. Work involving the augmentation of objects other than writing utensils or musical instruments includes the Sonic City system [22], in which the urban environment served as the interface. The Bluetooth Radio Ball Interface (BRBI) [59] augmented a sport ball with sensors, providing sound and music capabilities (mediated by a computer and a Bluetooth radio connection). The Urban Musical Game [48] was another augmentation project involving a sport ball and sound/music generation based on the ball's motions; video of use of Urban Musical Game have been made available on Vimeo (https://vimeo.com/26413625) and (https://vimeo.com/22120867). Measurement of writing motions helps diagnose people suffering from obsessive-compulsive disorder [43]. Handwriting and cell-phone texting have been compared as therapies for Broca's aphasia, with handwriting emerging as the more effective treatment [4]. Embodied cognition models have been used to investigate neural relationships with character writing, copying, and recognition [35]. Preschool children have taken part in fMRI experiments, which demonstrate the importance of "learning-by-doing" approaches to literacy learning, with kinesthetic activity working in tandem with cognition [34]. Existential phenomenology has informed 
thought regarding the teaching of personal writing, without any technological involvement [33]. Recent work by Kiefer [36] has found neuropsychological evidence for benefits from writing by hand, as opposed to writing using a computer keyboard, including improved learning of reading and writing skills in young children. Morphy and Graham [44] argue students more generally, appear to write better when using word processors than when composing by hand, considering the composition tools (spell check, grammar check, etc.) available in modern word processing software. Al-Ghabra [1] focused on the importance of handwriting for the development of composition skills in college students. Earlier work by Collier and Werier [7] found no difference between high-level characteristics of textual production in proficient adult writers who composed either by hand or while using a word processor.

\subsection{Development of Work}

Thoreau [58] decried some forms of letter writing, writing that, "The penny-post is, commonly, an institution through which you seriously offer a man that penny for his thoughts which is so often safely offered in jest"; from a different viewpoint, writing letters has been a way for families to stay connected through the generations and has functioned alongside newer media [47]. Twentieth-century German philosopher Martin Heidegger commented, in his Parmenides, upon handwriting, declaring its superiority over use of a typewriter [28]. Philosopher of technology Don Ihde[31] faulted Heidegger for Heidegger's comparison. Philosopher Jacques Derrida [18] also faulted Heidegger, for implying, while emphasizing the importance of "the hand" for humanity, that human beings only have one hand. A typewriter does not offer the affordance [19] of being easily carried up a mountain-although Nietzsche owned a portable typewriter [3] and hiked up the mountains. Likewise, the poem title of a friend, "Notebooks," [39] would read differently if it had to do, not with notebooks, but with some digital note-taking contrivance such as Google's Keep app (http://keep.google.com). Ihde reminds us of the non-transparency of electronic and digital communications media such as the telephone [30], and here, with Nietzsche's typewriter and Gregory Lawless's poem, we see some effects of medium, in practice (typewriter) and in discourse (poem title).

Heidegger [26] decries what he sees as hastiness in the face of a technologically facilitated information glut. Both Heidegger [26] in his "Memorial Address," and Jacques Ellul [20] in The Technological Society, declare technology to have become "autonomous" (in Ellul's phrasing), saying its progression could not be stopped, even if human beings wanted to stop it. Our thinking here is that technology creates more options, including the option to not use it; non-users of a technology have been considered by Satchell and Dourish [50]. Should we augment human capability, or should we replace it with a technological contrivance? As discussed above, we have followed Machover in choosing to augment human creative capability, using Line-Storm.

\subsubsection{Creativity and Line-Storm}

For work done by Csikszentmihalyi, ninety-one persons were interviewed who were deemed to have made significant contributions to their fields [11]. Many others, who excluded themselves from his study, were skeptical of studying creativity or of participation in the study as being worthy of their time, and some insisted they were too busy being creative to stop and talk about it [13]. A direct approach to enhancing creativity, Csikszentmihalyi [13] writes, is less effective than are attempts to place the creative worker in a favorable environment; but beautiful surroundings are not what he means. The creative worker creates an environment conducive to creative thought and work, despite otherwise unfavorable surroundings; creative people provide a personal pattern" [15]. On the other hand, he denies there is proof that a person needs "delightful" surroundings to engage in creative work [12]. Our work attempts to alter the state of the creative worker, short of accomplishing shamanistic technique or administering psychedelics . Csikszentmihalyi makes a similar claim for the creative worker. The creative worker has their attention focused in areas outside the "status quo" [15]. Creativity is lauded widely yet creativity works for good and bad. Cropley $[10,9]$ wrote that a computer hacker who circumvents security measures to steal money, has exhibited creativity no less than a symphonic composer imagining a new melodic line. Sternberg [57], writing of what is known about creativity, iterates two points: (1) creativity is mostly "domain-specific," and (2) it is partly independent of measured intelligence quotient (IQ).

\subsection{Creativity as Play, and usability}

Much ink, including that of Thoreau [58], has been spilled comparing creativity to play. Play does not need the context of a game, to be play. Play may be contrasted with the world of production and work. In attempting to provide an immersive experience conducive to the presence and engagement of the creative worker. Schechner [52] has described the "actual" and the roughness of the performance of writing the poem as "the genuine meeting between performer and problem"; having a sense of presence and engagement is a desirable state for creativity. Dan Ariely [2] wrote that money is a poor motivator to creative production [2]. According to Ariely [2], it is not clear how much of our "mental activity" is under our "direct control," especially when we are working under pressure. Our 
system might prove more difficult to use than ordinary pencil and paper, and this is not in itself a problem for us because creativity is different than usability. In addition creativity may not be fully mechanizable. Creativity is not only randomness or sheer novelty; it requires filtering by an intelligence [51]. Counterintuitive incentivisation may be called for when attempting to stimulate creativity. Making a task more difficult through the use of unusual tools, may stimulate creative production. Changing the affordances [19] of a once-familiar taskscape [32], may be key to inducing creative thought, making one see a thing or activity in a new way.

\subsubsection{Engagement and Preservation in Line- Storm}

Line-Storm is interactive. It augments an ordinary pencil and an ordinary pad of paper, adding new interaction possibilities, new affordances [19]. It responds to the person engaged in using it-and it is immersive. The headphones may make it "easy to forget the outside world," allowing the user to "concentrate completely" on the writing task [12] on hand because that is allowable.

Line-Storm is an attempt at providing creative workers with a new tool. Citing Edward Tenner, Runco [49] cautions that tools do not have to be poorly made or poorly designed or have "an undesirable feature, to cause problems" involving either the creative worker or others. Combining technology (pen and soundscape) with art (poem or content) and art works does not, in itself, enhance creativity [49]. In this paper, we argue that for some people Line-Storm provides an opportunity for creativity. Han [24], and Bohme [5], question the place of technologies in our lives, and the role of the associated, technological, perspective in dominating other forms of life. Lucas observed of the world depicted in his 1971 film, $T H X 1138$, that "nobody was having any fun, but no one was unhappy" [17]. As mentioned earlier, the enhanced pen/techology provided an opportunity for creativity in Line-Storm. We have made a new piece of technology that is based on fun. We tread softly when we attempt to bring new technologies into the practice of writing or drawing by hand with pencil and paper.

\section{IMPLEMENTATION}

We present the details of our implementation of LineStorm.

\subsection{Development Environment: Max/MSP}

We implemented the software interface and soundsynthesis engine of Line-Storm using Max/MSP,
Version 7.2.3, 64-bit edition. Max/MSP is the mature, commercial successor to Miller's Pure Data (https://puredata.info/downloads/pure-data), a free and open-source project. Like its predecessor, Max/MSP is a graphical programming environment. Objects in the Max/MSP GUI windows can be interconnected and otherwise manipulated inside patchers (graphical representations of program files in Max/MSP) (Figure 2).

Max/MSP has further advantages over some other music-synthesis DAWs such as FM8; Max/MSP is programmable, and it is well-documented.

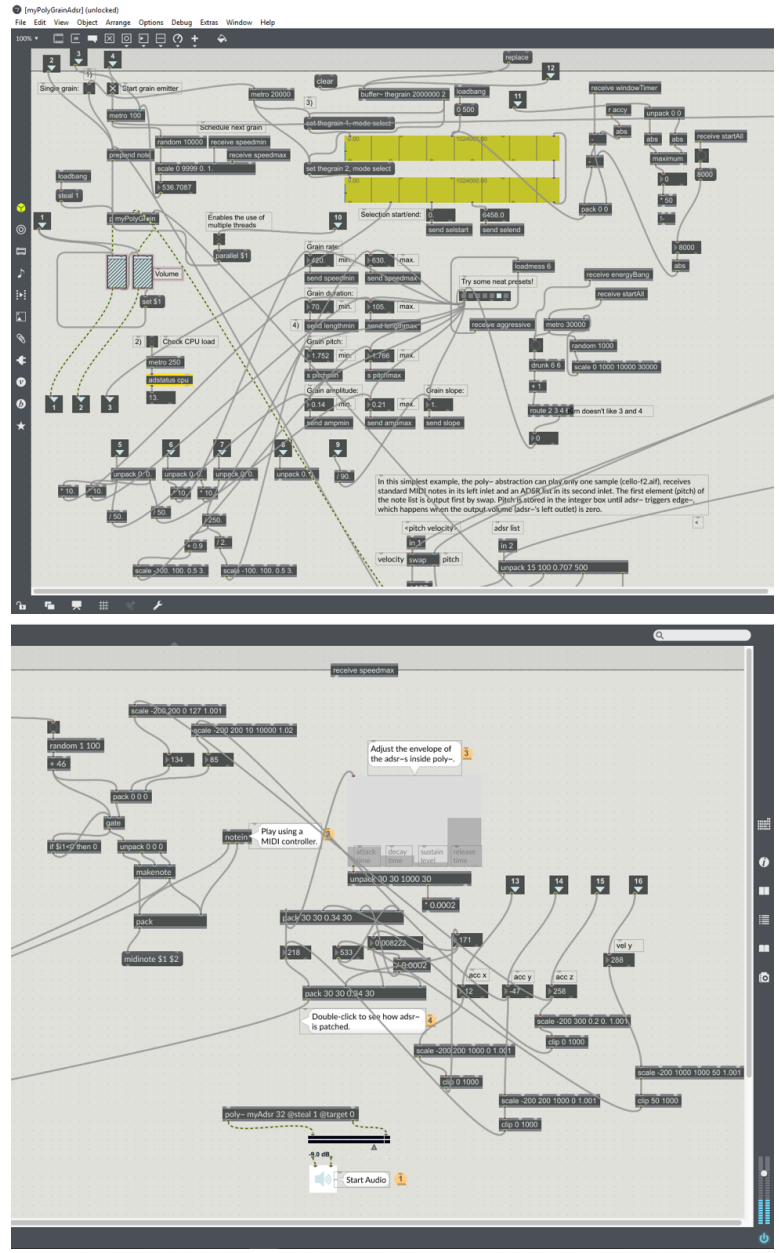

Figure 2: above): Line-Storm (above) Granular synthesis engine in Max/MSP (ADSR envelope generator offscreen to right); (below)ADSR envelope generator for granular-synthesis engine.

\subsection{Sensor-Fob Construction}

The sensor-fob, shown above, in Figure 1(a-c), comprises multiple PCB circuit-boards, powered by a lithium-polymer battery, and five solid-core, insulated copper wires soldered between two of the PCB circuit-boards. 
The primary board is an Arduino Fio v3 microcontroller board. This type of Arduino board includes a socket into which an XBee radio transceiver module can be inserted. The Fio v3 can control the inserted XBee radio transceiver module. We have a Digi International XBee radio transceiver module (type $\mathrm{S} 1$ ) inserted into the socket of our Fio v3. The Fio v3 has multiple GPIO/ADC (general purpose input/output or analog-todigital converter) pins, three of which we have soldered wires to. These three wires are soldered at their ends, to an Adafruit ADXL335 3-axis accelerometer, to its three, analog output-signal pins. Two more pins, and two more wires, connect Vcc and GND on the Fio v3 and ADXL335. The wires are rigid; they both connect the boards and hold them in constant positions relative to each other, in a fixed orientation, by soldering connections between the Fio v3 and the ADXL335.

\subsubsection{Accelerometer}

We used an Adafruit ADXL335 3-axis accelerometer mounted to a breakout board. Moving the sensor-fob, with its attached ADXL335 unit, in as violent a manner as we were able to do while holding it with a hand, we sometimes reached minimum and maximum sensoroutput values, but not always; reaching these values was difficult. Lesser motions were well within the $+/-3 g$ range, giving sensor output values below the approximately 1000 maximum and above the approximately 0 (zero) minimum. Sensor output values, raw from the GPIO/ADC pins, range from 0 to approximately 1000 , with a center value of approximately 500. This range is compatible with an 8-bit ADC, which the Fio v3 uses. Values below about 500 indicate negative accelerations relative to the corresponding sensor axis, while values above 500 indicate positive accelerations relative to the corresponding sensor axis.

\section{EVALUATION: IRB STUDY}

Our study involved participation by thirteen persons, but data for one of these participants was discarded, leaving twelve participants with valid data. We had roughly half female and half male, including one who chose not to self-identify. Participant ages are ranged from 18 years to 34 years.

\section{DATA ANALYSIS AND RESULTS}

As creativity and engagement is somewhat fleeing and vary from one person to another, research hypothesis, that participants' sense of presence and engagement would be greater during the experimental, interactive condition than during the control, non-interactive condition was not directly supported, instead it was only supported by a smaller group of our participants. This was not so unexpected result.
We performed Pearson correlations, and found several statistically significant correlations, discussed below. For example, those participants who reported they lost track of time during the experimental condition also tended to write more during the experimental condition. There was a non-significant correlation between losing track of time and word count during the control condition.

To perform our statistical analyses, we used IBM's SPSS Statistics, Version 25 (https://www.ibm.com/products/spssstatistics), because it is an industry standard statistics processing application.

\subsection{Summary of statistical analysis}

- There were strong, significant $(\mathrm{p}<0.01)$ correlations between the initial, baseline level of a sense of presence and engagement and response items 4 (NAT) and 7 (ADJEXP), for both control and experimental conditions.

- A sense of presence and engagement correlated strongly and significantly $(\mathrm{p}<0.01)$ with adjustment to the "control devices" (augmented stylus, augmented writing pad) (ADJCTL) for both control and experimental conditions.

- There were strong, significant correlations between a sense of the naturalness of interactions with the system and baseline sense of presence and engagement, ease of adjustment to the system experience, and ease of adjustment to the control devices (ADJCTL), for both control and experimental conditions. We found that participants found their interactions with the system more natural during the control condition, and less natural during the experimental condition. Participants adjusted to the system experience more quickly during the control condition than they did during the experimental condition.

- There was a group of participants who responded more favorably to the experimental condition than the rest of the participants (analysis performed using $\mathrm{K}$-means clustering tests). This is a significant result for our experiments.

- Those who wrote more in the control condition wrote more in the experimental condition. This is also a significant result for our experiments.

- The more participants lost track of time, in the experimental condition, the more they wrote-or vice versa. This is a significant result for our experiments.

- We found correlations between a sense of presence and engagement during the experimental condition (PANDE1), and the degree to which a participant lost track of time while using the system during the 
experimental condition. This is a significant result for our experiment, and we call these participants as the Preservers of Line-Storm .

Our findings indicate that there appears to have been a significant group of participants, roughly half the participants, the Preservers of Line-Storm, who became immersed during the experimental condition. These participants tended to write more during the control and experimental conditions, they tended to experience the sound components of the system (control and experimental) in a way that led to their reporting less prominence of the visual aspects of the system, and they tended to lose track of time during the experimental condition.

It seems likely that attention fluctuates over time, and the mind naturally wanders and returns. Future work would include investigation of the ways such natural fluctuations in attention would be relevant to our work. Considering the ordering of questionnaire completion was nearly always the same (Demographic, Experimental, Control), natural fluctuations in attention (and presence and engagement) may help to explain our results. Considering how we might have been wearing out our participants, by making demands upon their attentional resources, future work might be done that minimized attentional fatigue.

First, as equipment, Line-Storm is a tool we have made for a purpose. As equipment, Line-Storm has a thingly character and an equipmental character. As a thing, Line-Storm exists as an object that can be encountered in the world, like a rock.

As art work, the art-work is the creation Line-Storm due to interaction - whatever the user does is recorded on the pad and the performance is the sound created for the user so that they are engaged perhaps because of the sound. As art work, Line-Storm is bringing forth of the work that there lies this offering that it be [27]. When we evaluated Line-Storm in terms of its capacity for leading to a possible increase in self-reported presence and engagement, we treated it as equipment. Yet some participants, while using Line-Storm, treated it not as equipment but as art work. Hence, we will refer to the group of participants who gave higher ratings to LineStorm, and who wrote more while using it, as the Preservers of Line-Storm. The Preservers let Line-Storm be what it is. Without the Preservers, Line-Storm "cannot itself come into being" [27]. We use Heidegger's nation of "preserver," someone who allows the work to be what it is, who brings themselves to the work, Line-Storm, letting themselves experience the writing task and familiar materials?pencil and paper?as if for the first time ([27].

\subsection{Performance Affordances in Line- Storm}

Line-Storm permits itself to be used in performance. A performance with Line-Storm could be understood to point out the overlapping of sensory or perceptual modes commonly thought of as separate. Seeing, hearing, moving, and proprioception involve cross-modal transfer [56]. The sound and visual aspects overlap more strongly in Line-Storm than in ordinary writing or drawing, because of the amplification of what had been quiet sounds, i.e. the sound made by stylus on the paper which was amplified and merged with other sounds, such as thunderstorm. Line-Storm makes affordances prominent, in the writing stylus and writing pad, that may not have been apparent: their sound-producing capabilities, which can be used in a performance. Preservers of Line-Storm find its affordances.

\subsection{Robotany and Line-Storm}

In 2006, a living Japanese maple tree was augmented with nitinol wires and optical and audio sensors. The tree moved its branches, using the nitinol "muscle" wires, in response to the presence of people detected by its sensors. When the mechanical components were hidden from view, during the first exhibit, interactions took place with people treating the tree as ready-tohand. The mechanical components of Breeze withdrew, became transparent, and the people at the first exhibit interacted with Breeze as an interactive art work. During the second exhibit, with the mechanical components poorly hidden by the tall, open shape of the mountain laurel, attendees at the exhibit tended to comment on the engineering of Breeze instead of interacting with it freely as had the attendees during the first exhibit. This is quite interesting for our implementation as well.

\section{A LUDIC ENVIRONMENT FOR THE PRESERVERS OF LINE-STORM}

We conceived our work, initially, as an entertainment system, to be used for one's own pleasure while writing in a journal. We followed that by hoping to jolt users out of complacent acquaintance with paper and pencil and present the writing tools and writing situation as if for the first time, to encourage the practice of writing and sending handwritten letters. We finished the work by attempting to enhance human creativity when working with a writing stylus and paper writing pad, by increasing participants' sense of presence and engagement. We found correlations and K-means clustering results that did suggest there was a group of participants who responded favorably to Line-Storm.

We expected that a direct approach to enhancing creativity may/would fail; we attempted to construct a system the use of which would be an end and not only 
a means [21], and hoped this might lead, indirectly, to enhancing creativity by encouraging play and playfulness. We provided a ludic environment for creative work, in which some users would focus on using the system, not expecting an outcome and will create their own play/outcome and accept what emerges or not-no quest, no winners, no points or gold to deliver outcomebased satisfaction. In a ludic system, therefore, the creative work (outcome is what it is) and the results would be a secondary consideration and may emerge by itself, an indirect result of the use of the system. We hoped participants in our experiments would find themselves "losing themselves," and a group of participants did tend to lose track of time while they used or performed with Line-Storm. We believe these participants became more absorbed while using the experimental system, exactly our intention. Losing oneself while using the system might open one up to creative energies, thoughts, feelings, and actions that would ordinarily not occur, as Nietzsche [45] wrote.

The Preservers of Line-Storm differ from the other experimental participants. They have a type of knowing (pg. 192 [27]). They allow themselves to explore the world opened by Line-Storm (pg. 169 [27]). They "[let] the work be a work" (pg. 191 [27]). They heed the call of Line-Storm, noticing its statement: "that it is" (pg. 190 [27]). For them, pencil and paper, and the writing task in which they engage, is new, fresh, and they experience what had become a commonplace activity, anew (pg. 171 [27]).

\section{CONCLUSIONS AND FUTURE WORK}

One component of Line-Storm is its interactivity. A certain type of actions and intentions are required on the part of the participant for Line-Storm to be what it is. Coffin wrote of Breeze, and of interactive systems more generally, that interactions with them may be "effortless, unscripted, emergent, and engaged" if the mapping of responses is well done with respect to our "meaning-making sensibilities" [6]. Our goal that Line-Storm would provide for increased presence and engagement was not met for all participants. Still, some participants appeared to have had fun and play while using Line-Storm. Some of these participants likely experienced Line-Storm as art work, and so we would have found preservers for our work, who brought out its workly character, and who would belong to it just as we belong to it as its creators. This justifies our efforts. The participants' prior knowledge is relevant when considering their responses to Line-Storm. Line-Storm, as a tool, exists not by itself but among a constellation of related tools; those related tools, some of which a given participant may be familiar with, and some of which they may not be familiar with, allow Line-Storm "to be this equipment that it is" [25]. A participant's degree of familiarity with related tools, such as an envelope, stamp, mail-box, and pencil and paper, help to determine what Line-Storm is for that participant. We see a nearly significant $(\mathrm{r}=0.620, \mathrm{p}=0.056)$ correlation of current writing or drawing (by hand) practice to number of words written while using Line-Storm. We think that, this correlation indicates participants who regularly wrote or drew by hand were better able to experience Line-Storm as it was intended, and see its' authenticity.

Future work would include the following items, listed as follows: (a) We would reinstate the capability of triggering multiple thunderstorm samples in rapid sequence. (b) Make a cover for the electronic components on the sensor-fob. (c) Extension to a mobile platform (d) Investigate the use of more miniaturized RF components. We do not need the relatively large antennae of the XBee radios, which can operate over a larger distance than we envision for the use of our system. Bluetooth would provide the necessary range. (e) Investigate using more miniaturized micro-controller boards. The Arduino Fio v3 was the smallest board we found, when we began our work, with all the functionality we needed. A smaller board would make a less intrusive sensor-fob. (f) Experiment with different styli, including a paintbrush, a child's crayon, a marker, a piece of chalk, a paint roller, and so on. Attaching a contact microphone to the surfaces used with many of these would probably produce a suitable-strength vibration for use with our system. (g) Experiment with a baton-type stylus like the one used by Paradiso and Machover in the Brain Opera. (h) Investigate a wrist-worn appliance to augment or replace the motion-tracking capability of the stylus sensor-fob. (i) Gather more data involving a larger sample size. (j) Vary the type of music listened to during the control condition. (k) Consider ways to run experiments without wearing out participants by making excessive demands on their attention. (1) Experiment with a multi-user system. Users could be situated in the same place or could communicate via a computer network such as the internet. (m) Collaborate with music composer of electroacoustic music. Collaborating with a person skilled in the creation of electronic music would be of great benefit in future as well.

Finally, it has occurred to us that Line-storm as an augmentation itself is innovative. Augmenting means a possibility that is completely different than the original which Line-Storm is. The Preservers of Line-Storm, in our experiments, showed that there is promise for our augmented interface. Creativity is difficult to capture and define. Still, our work provided a completely different experience through augmented interaction to creative writing which enhanced the user experience, enhancing ordinary pen and paper. 


\section{REFERENCES}

[1] I. M. Al-Ghabra. Handwriting: A matter of affairs. English Language Teaching, 8(10):168178, 2015.

[2] D. Ariely. The Upside of Irrationality. HarperCollins, New York, 2010.

[3] S. Avnskog. Friedrich nietzsche and his typewriter - a malling-hansen writing ball), February 2008.

[4] P. M. Beeson, K. Higginson, and K. . Rising. Writing treatment for aphasia: a texting approach). Journal of Speech, Language, and Hearing Research, 56(3):945, 2013.

[5] G. Böhme. Invasive Technification: Critical Essays in the Philosophy of Technology. Bloomsbury, New York, 2012.

[6] J. Coffin. Robotany and lichtung: a contribution to phenomenological dialogue. In Proceedings of the Second International Conference on Tangible and Embedded Interaction, pages 217-220, Bonn, Germany, 2008. ACM.

[7] R. Collier and C. Werier. When computer writers compose by hand. Computers and Composition, 12:47-59, 1995.

[8] N. Collins, M. Schedel, and S. Wilson. Electronic Music. Cambridge UP, Cambridge, England, 2013.

[9] A. J. Cropley. Acknowledgements. In The Dark Side of Creativity, pages 1-14. Cambridge UP, Cambridge, UK, 2010.

[10] A. J. Cropley. The dark side of creativity: What is it? In D. H. Cropley, editor, The Dark Side of Creativity. Cambridge UP, A. J, 2010.

[11] M. Csikszentmihalyi. Acknowledgements. In Creativity: Flow and the Psychology of Discovery and Invention, pages vii-viii. HarperCollins, New York, 1996.

[12] M. Csikszentmihalyi. Creative surroundings. In Creativity: Flow and the Psychology of Discovery and Invention, pages 127-147. HarperCollins, 1996.

[13] M. Csikszentmihalyi. Setting the stage. In Creativity: Flow and the Psychology of Discovery and Invention, pages 1-20. HarperCollins, 1996.

[14] M. Csikszentmihalyi. Flow, the secret to happiness, 2004.

[15] M. Csikszentmihalyi. Motivation and creativity: Towards a synthesis of structural and energistic approaches to cognition. In Flow and the Foundations of Positive Psychology: The Collected Works of Mihaly Csikszentmihalyi, pages 155173. Springer, New York, 2014.
[16] R. Dass. Be Here Now. Lama Foundation, San Cristobal, NM, 1971.

[17] M. T. Decker. They want unfreedom and onedimensional thought? i'll give them unfreedom and one-dimensional thought: George lucas, thx1138 , and the persistence of marcusian social critique in american graffiti and the star wars films. Extrapolation, 50(3):417-441, September 2009.

[18] J. Derrida. Geschlecht ii: Heidegger's hand. In J. Derrida and J. Sallis, editors, Deconstruction and Philosophy: The Texts of Jacques Derrida, pages 161-196. Univ. Chicago Press, Chicago, 1987.

[19] P. Dourish. Being-in-the-world. In P. Dourish, Where the Action Is: The Foundations of Embodied Interaction, pages 99-126. MIT Press, Cambridge, MA, 2001.

[20] J. Ellul. The Technological Society. Alfred A. Knopf, 1964.

[21] B. Gaver. Designing for homo ludens, still. In T. L. J. Binder, editor, (Re)Searching the Digital Bauhaus, pages 163-178. Springer-Verlag, London, 2009.

[22] L. Gaye, R. MazÃ(C), and L. E. Holmquist. Sonic city: The urban environment as a musical interface. In Proceedings of the 2003 Conference on New Interfaces for Musical Expression (NIME03), pages 109-115, Montreal, Quebec, Canada, 2003. ACM.

[23] N.-w. Gong, M. Laibowitz, and J. A. Paradiso. Musicgrip: A writing instrument for music control. In Proceedings of the International Conference on New Interfaces for Musical Expression 2009, pages 74-77, Pittsburgh, PA, 2009. New Interfaces for Musical Expression.

[24] B.-C. Han. Psychopolitics: Neoliberalism and New Technologies of Power. Verso, 2017.

[25] M. Heidegger. Being and Time. Harper Perennial, New York, NY, 1962.

[26] M. Heidegger. Memorial address. In Discourse on Thinking, pages 43-57. Harper \& Row, 1966.

[27] M. Heidegger. The origin of the work of art. In D. F. Krell, editor, Martin Heidegger: Basic Writings, pages 139-212. HarperSanFrancisco, San Francisco, 1993.

[28] M. Heidegger. Concealment and forgetting. In A. Schuwer and R. Rojcewicz, editors, Parmenides, pages 77-86. Indiana UP, 1998.

[29] R. Hougaard and J. Carter. If you aspire to be a great leader, be present. Harvard Business Review, 29, June 2017.

[30] D. Ihde. The technological embodiment of media. In Existential Technics, pages 47-63. SUNY 
Press, 1983.

[31] D. Ihde. Postphenomenological re-embodiment. Found Sci, 17:373-377, 2012.

[32] T. Ingold. On the temporality of the landscape. World Archaeology, 25(2):152-174, October 1993.

[33] L. Jacobs. Existential phenomenology and personal writing. College Composition and Communication, 26(3):293-297, October 1975.

[34] K. H. James. Sensori-motor experience leads to changes in visual processing in the developing brain. Dev Sci, 13:2, March 2010.

[35] K. H. James and I. Gauthier. Letter processing automatically recruits a sensory-motor brain network. Neuropsychologia, 44:2937-2949, 2006.

[36] M. Kiefer, S. Schuler, C. Mayer, N. M. Trumpp, K. Hille, and S. Sachse. Handwriting or typewriting? the influence of pen- or keyboard-based writing training on reading and writing performance in preschool children. Advances in Cognitive Psychology, 11(4):136-146, 2015.

[37] M. A. Killingsworth and D. T. Gilbert. A wandering mind is an unhappy mind. Science, 330(6006):932, November 2010.

[38] H. Kuchler. How silicon valley rediscovered lsd. Financial Times, 29, August 2017.

[39] G. Lawless. Notebooks. In Foreclosure, page 10. Back Page Books, Waltham, MA, 2013.

[40] T. Machover. Hyperinstruments: A Progress Report, 1987-1991. MIT Media Laboratory, Cambridge, MA, 1992.

[41] T. Machover. Hyperstring Trilogy [Recorded by A. Kavafian, K. Kashkashian, \& M. Haimovitz]. Oxingale Records, 2004.

[42] T. Machover. Dreaming a new music. Chamber Music, 23(5):46-54, 2006.

[43] P. Mavrogiorgou, R. Mergl, P. Tigges, J. El Husseini, A. Schroter, G. Juckel, and M. Zaudig. Kinematic analysis of handwriting movements in patients with obsessive-compulsive disorder. $J$ Neurol Neurosurg Psychiatry, 70:605-612, 2001.

[44] P. Morphy and S. Graham. Word processing programs and weaker writers/readers: a metaanalysis of research findings. Reading and Writing, 25(3):641-678, 2012.

[45] F. W. Nietzsche. The Gay Science: With a Prelude in Rhymes and an Appendix of Songs. Vintage Books, New York, NY, 1974.

[46] J. A. Paradiso. The brain opera technology: New instruments and gestural sensors for musical interaction and performance. Journal of New Music Research, 28(2):130-149, 1999.
[47] E. Pecorale. Writing to Maintain Relationships: From Letter Writing to Facebook: Crossing Borders, Generations, and Mediums. PhD thesis, ProQuest Dissertations Publishing, 2012.

[48] N. Rasamimanana, E. FlÃ@ty, F. Bevilacqua, A. Cera, J. Bloit, and U. Frechin, J.-L. ... Petrevski. The urban musical game: Using sport balls as musical interfaces. In CHI, pages 1027 1030, Austin, TX, 2012. ACM.

[49] M. A. Runco. Enhancement and the fulfillment of potential. In M. A. Runco, editor, Creativity: Research, Development, and Practice, pages 319-373. Academic Press, 2007.

[50] C. Satchell and P. Dourish. Beyond the user: Use and non-use in hci. In OZCHI 2009: Design: Open 24/7: 21st Annual Conference of the Australian Computer-Human Interaction Special Interest Group (CHISIG) of the Human Factors and Ergonomics Society of Australia (HFESA), Melbourne, 2009. The University of Melbourne.

[51] K. R. Sawyer. The emergence of creativity. Philosophical Psychology, 12(4):447-469, 1999.

[52] R. Schechner. Actuals. In R. Schechner, editor, Performance Theory, pages 26-65. Routledge Classics, New York, NY, 2003.

[53] R. Schechner. Performance Studies: An Introduction. Routledge, New York, 2006.

[54] T. Shichinohe, T. Yamable, T. Iwata, and T. Nakjima. Augmented calligraphy: Experimental feedback design for writing skill development. In TEI'11, pages 301-302, Funchal, Portugal, 2011. ACM.

[55] C. Springob. Why is it easier to see a star if you look slightly to the side? Ask an Astronomer, Jun 2015.

[56] N. Stern. Interactive Art and Embodiment. Gylphi Ltd, Canterbury, England, 2013.

[57] R. J. Sternberg. Preface. In R. J. Sternberg, editor, Wisdom, Intelligence and Creativity Synthesized, pages ix-Xviii. Cambridge Univ. Press, New York, NY, 2003.

[58] H. D. Thoreau. Where I lived, and what I lived for. In H. D. Thoreau, editor, Walden, or Life in the Woods, pages 67-79. Collier Books, New York, 1962.

[59] W. S. Yeo. The bluetooth radio ball interface (brbi): A wireless interface for music/sound control and motion sonification. International Computer Music Conference 2006 (ICMC 2006), 2006. 